\title{
The impacts of land cover change on stream discharges in Luvuvhu River Catchment, Vhembe District, Limpopo Province, South Africa
}

\author{
F. I. Mathivha ${ }^{1}$, P. M. Kundu ${ }^{1}$ \& L. R. Singo ${ }^{1,2}$ \\ ${ }^{1}$ Department of Hydrology and Water Resources, \\ University of Venda, South Africa \\ ${ }^{2}$ Process Technology Department, Rand Water, South Africa
}

\begin{abstract}
Luvuvhu River Catchment experiences floods resulting from heavy rainfall intensities exceeding $15 \mathrm{~mm}$ per hour. The generation of runoff is triggered by the rainfall intensity and soil moisture status. In this study, remote sensing and GIS techniques were used to analyse the hydrologic response to land cover changes. Runoff was calculated as a product of the net precipitation and a curve number coefficient. It was then routed using the Muskingum-Cunge method using a diffusive wave transfer model that enabled the calculation of response functions between start and end point. Flood frequency was determined using theoretical probability distributions. Spatial data on land cover was obtained from multi-temporal Landsat images while data on rainfall, soil type, runoff and stream discharges were obtained by direct measurements in the field, Department of Water Affairs and from the South African Weather Services. The results showed that land cover changes had impacted negatively on the hydrology of the catchment. Peak discharges in the catchment were noted to have increased by $17 \%$ over the study period while flood volumes were noted to have increased by $11 \%$ over the same period. The synergism between remotely sensed digital data and GIS for land surface analysis and modelling was realised, and it was therefore concluded that hydrologic modelling has potential for determining the influence of changes in land cover on the hydrologic response of the catchment. Keywords: catchment, flood, GIS, hydrology, hydrological model, rainfall, remote sensing, runoff, soil.
\end{abstract}




\section{Introduction}

Luvuvhu River Catchment experiences floods resulting from heavy rainfall associated with the Intertropical Convergence Zone (ITCZ) and cyclonic rains related to global warming and climate change. Land cover and land use change in the catchment are a major cause of environmental concern. Water resources are gradually getting depleted due to uncontrolled anthropogenic activities related to the rising human population. Lack of appropriate land and water management strategies lead to land degradation by soil erosion, increased runoff and sedimentation during rainfall events Department of Water Affairs and Forestry (DWAF) [1]. It is therefore imperative that studies to investigate, detect and quantify the land cover changes and their potential impact on the hydrological processes be carried out to provide baseline information for management purposes. In order to analyse flood flow, distributed channel flow routing models which employ convective diffusion equations to estimate flow characteristics at various stages within the river channel can be used. Since river stage is required for the design and evaluation of hydraulic structures, flood routing techniques can be utilised to estimate the stages in order to predict flood wave propagation along river reaches. This is because, most river reaches in the study area are ungauged and a methodology is needed to estimate rates of flow at specific locations in rivers where no measurements are available.

Advances in remote sensing and GIS techniques have broadened the scope of global data acquisition, providing the capacity to quantify and estimate spatially distributed hydrological processes (Moore et al. [2], Carpenter et al. [3]). Satellite sensors including Landsat Enhanced Thematic Mapper plus (ETM+), High Resolution visible (SPOT HRV), Moderate Resolution Imaging Spectrometer (MODIS), Medium Resolution Imaging Spectrometer (MERIS) and National Oceanic and Atmospheric Administration (NOAA) among others, now provide repetitive land surface data and have made it possible to quantify multi-temporal variability of land cover (Coppin et al. [4]). Hydro-geophysical catchment parameters can be derived from the global digital soil and topographic datasets after which, computer-based hydrological models are applied to solve complex hydrological problems.

In this study, multispectral and multi-temporal remotely sensed data were integrated with hydro-meteorological data, soil data and ancillary data for spatial analysis and modeling within GIS. The purpose was to realise the synergism between remotely sensed digital data and GIS for land surface analysis and modelling. To route channel flow, the Muskingum-Cunge equation within the Geo-HMS 2000 software was used to evaluate the effects of land cover changes on flood volumes and peak discharges. Hydrological models for runoff generation, transformation and flow routing were applied for simulations using semi-distributed modeling techniques. 


\section{The study area}

The LRC shown in Figure 1 is located in Vhembe District Municipality of the Limpopo Province in northeastern South Africa, between latitudes 22 $17^{\prime} 34^{\prime \prime S}$ and $23^{\circ} 17^{\prime} 57^{\prime \prime S}$ and longitudes $29^{\circ} 49^{\prime} 46^{\prime \prime} \mathrm{E}$ and $31^{\circ} 23^{\prime} 32^{\prime \prime} \mathrm{E}$, and covers an area of about $5941 \mathrm{~km}^{2}$ DWAF [5]. The climate of the area is largely influenced by the ITCZ, modified by local orographic effects. Rainfall distribution in the catchment is classified as unimodal, having a rainy season predominantly between the months of October to January with the average annual rainfall of about 200-400 mm (Reddy [6]). Generally, the catchment exhibits diverse land use/land cover patterns that are influenced by seasonality and socio-cultural practices of the local communities. Land use practices largely vary from plantation forests interspersed with large scale macadamia and banana plantations in the headwater areas with small farm holdings for subsistence agriculture in the middle and lower reaches of the catchment.

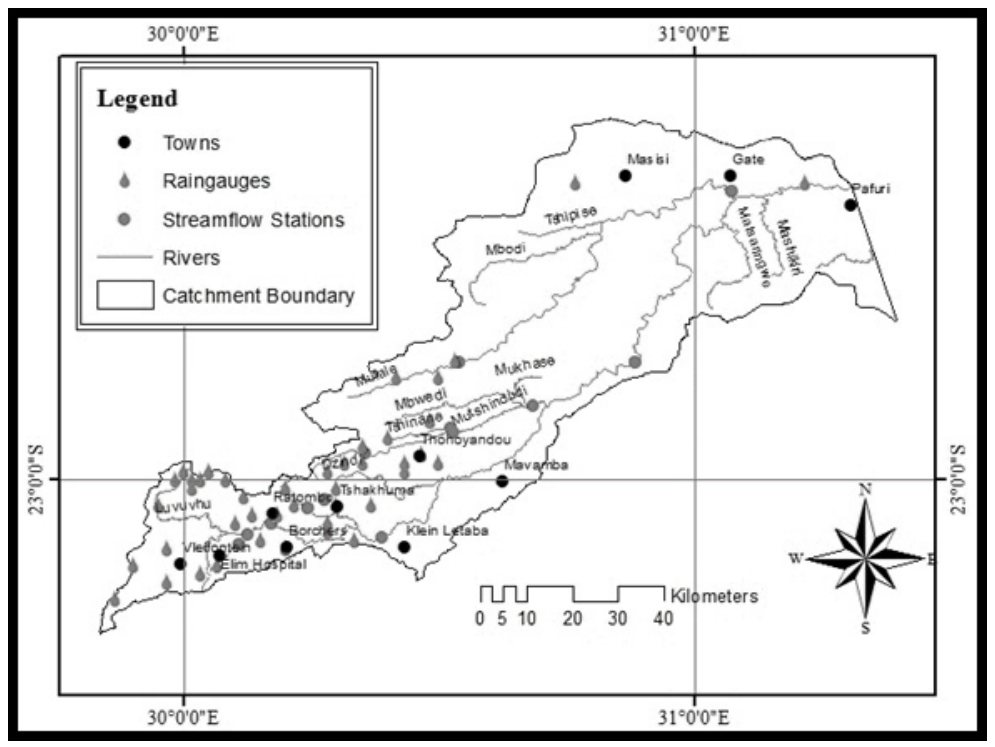

Figure 1: The study area.

\section{Materials and methods}

\subsection{Land cover}

Land cover was classified from Landsat MSS images for 1980 by visual interpretation based on analysis of false colour composites, while the land cover for 1989 and 2013 was classified from Landsat ETM+ using ERDAS software. Land cover changes were then detected and quantified through classifications of 
the same images. To minimize distorting spectral characteristics caused by mosaicking multi-date images before classification, the scenes were independently classified. The images were first resampled to a common spatial resolution using the nearest neighbor interpolation technique. The predominant land cover classes selected for the study included agriculture, forest, urban and peri-urban, grassland, shrub-land, bananas and water. To obtain consistent land cover classes for semi-distributed hydrological modeling, a per-pixel image classification approach was adopted where the images were classified based on guided clustering as described by Yuan et al. [7]. The accuracy of the quantified land cover changes was determined using the standard measures for assessing the accuracy of remotely sensed data referred to as the overall accuracy and the kappa index (Congalton and Green [8]). A majority filter was applied to remove isolated pixels arising out of the classification. The images were then converted into vector coverages which were used to derive the required land cover statistics within the derived sub-catchments.

\subsubsection{Soil data}

Digital soil data at a scale of 1:2 Million, were acquired from the Global Environment Facility Soil Organic Carbon database for the SADC countries. Soil data were reclassified into the major hydrological soil groups (HSG) of the catchment with the help of FAO/UNESCO revised manual for soil maps of the world based on their drainage characteristics. The World Reference Base for Soil Resources (WRB) classification FAO [9] was used as a unifying medium of communication.

\subsubsection{Hydro-meteorological data}

Rainfall and stream flow data between the period of 1962 and 2013 for the eight gauging stations located in the catchment were obtained from the South African Weather Services (SAWS) and Department of Water Affairs (DWA) respectively. GIS tools were used to create layers for the various data sets including the catchment boundary, stream lines and the meteorological stations. The flood frequency for the period of 50 years was analysed using Gumbel [10] extreme value method shown in eqn (1). This method is more appropriate for obtaining better outcomes for larger extrapolations of flood data.

Gumbel's equation

$$
P\left(X-\geq x_{0}\right)=1-e^{-e^{-y}}
$$

where, $\mathrm{P}=$ the probability of occurrence, $\mathrm{X}=$ the event of the hydrologic series, $\mathrm{x}_{\mathrm{o}}=$ the desired value of the event, $\mathrm{y}=$ the reduced variate $=\alpha(x-a)$ and $\mathrm{x}=$ the variate value.

To model the catchment response to changes in land cover, event based simulations were carried out where three typical storm events were selected and used as input to the rainfall-runoff models for scenario analysis. Three scenarios and the land cover conditions for 2013 were analysed. Scenarios 1, 2 and 3 represented the land cover conditions for 1989, 1980 and surface condition 
before 1980 respectively. The latter is based on the six summary land use classes described by the Agricultural Research Council (ARC). The analysis for 2013 was based on measured data for comparison and assessment of the simulation results. The base scenario which had less cultivation and built up was simulated by decreasing the Curve Number $(\mathrm{CN})$ while the degraded land surface scenarios were simulated by increasing the $\mathrm{CN}$. To assess the impact of the land cover changes, synthetic storm events of varying magnitudes assumed to be uniformly distributed and with the same duration in the sub-catchments were selected for scenario analysis. The storm events were applied at nominal depths to the different land cover conditions to investigate the possible effects on the peak discharges, based on the analysed trends of the rainfall records acquired.

\subsection{Model parameterization}

The hydrological models which were adopted included the Natural Resource Conservation Service-Curve Number (NRCS-CN), Clark's Unit Hydrograph (C$\mathrm{UH}$ ), and the Muskinghum-Cunge flow routing models available within the Hydrologic Modeling System (HEC-HMS) HEC-HMC [11]. Transformation of the runoff into corresponding hydrographs at the outlet of the catchment was achieved using the C-UH concept HEC-HMC [12]. The time of concentration was estimated from the lag time while the storage coefficient was estimated by relating the parameter to the time of concentration and the geometrical properties of the catchment. The exponential recession and empirically fitted parameter model was used to represent baseflow processes. The model required the determination of the recession constant and the initial baseflow, which was approximated from the baseflow trends during periods of high flow. Routing of the channel flow was performed using the Muskinghum-Cunge hydrologic model shown in eqn (2) (Cunge [13]), [10]. Estimates for the bank full depth, width of the river channel bottom and other flow characteristics were acquired from the Department of Water Affairs (DWA).

Muskingum-Cunge equation

$$
Q_{j+1}^{n+1}=C_{1} Q_{j}^{n}+C_{2} Q_{j}^{n+1}+C_{3} Q_{j+1}^{n}+C_{4} Q_{L}
$$

where,

$$
C_{1}=\frac{\frac{\Delta t}{k}+2 x}{\frac{\Delta t}{k}+2(1-x)} \quad C_{2}=\frac{\frac{\Delta t}{k}-2 x}{\frac{\Delta t}{k}+2(1-x)} \quad C_{3}=\frac{2(1-x)-\frac{\Delta t}{k}}{\frac{\Delta t}{k}+2(1-x)} \quad C_{4}=\frac{2\left(\frac{\Delta t}{k}\right)}{\frac{\Delta t}{k}+2(1-x)}
$$

$C_{1}, C_{2}, C_{3}, C_{4}=$ model coefficients, $K \cong$ travel time of wave through the reach, $\Delta t=$ change in time, $x=$ shape parameter, $I=$ inflow and $L=$ Lateral flow

The lengths of the river reaches and their slopes were derived from the DEM using Geo-HMS. The channel geometry at every reach of study and the Manning's roughness coefficient were estimated from field observations of 
the reaches and river bed materials using the method described by Cowan [14]. $\mathrm{CN}$ estimates for antecedent moisture conditions (AMC) were obtained from the standard $\mathrm{CN}$ tables for agricultural land use were used and later adjusted into AMC III, prevalent during floods in the catchment. The calculated $\mathrm{CN}$ were obtained using eqn (3) and eqn (4).

The Natural Resource Conservation Service-Curve Number (NRCS-CN)

$$
Q=\left(\frac{\left(P-I_{a}\right)^{2}}{P-I_{a}+S}\right)
$$

where, $\mathrm{Q}=\operatorname{runoff}(\mathrm{mm}) ; \mathrm{P}=$ rainfall $(\mathrm{mm}) ; \mathrm{I}_{\mathrm{a}}=$ initial abstraction $(\mathrm{mm}) ; \mathrm{S}=$ potential maximum retention after runoff begins $(\mathrm{mm})$.

Based on experiences from previous studies, the initial abstraction was assumed to be $20 \%$ of the maximum potential retention (S), which was related to the mean curve number parameter, by:

$$
S=\frac{25400}{C N_{m}}-254
$$

\section{Results and discussion}

\subsection{Land cover changes}

The quantified land use and land cover shown in Figures 2 and 3 provided data with consistent thematic representation of the cover classes in the selected segments. Figure 2 showed the area under forest/woodland, while Figure 3 showed the area under arable land. The pre-change geo-topes of planted forests and farms showed clear corridors, sizes, shapes and connectivity (Kundu et al. [15]). Analysis of the results in both Figures showed that the dominant land cover classes had changed tremendously by 1989 , where mixed classes of forest/woodland, grassland and shrubland covered $60 \%$ while agriculture and built-up area covered $40 \%$.

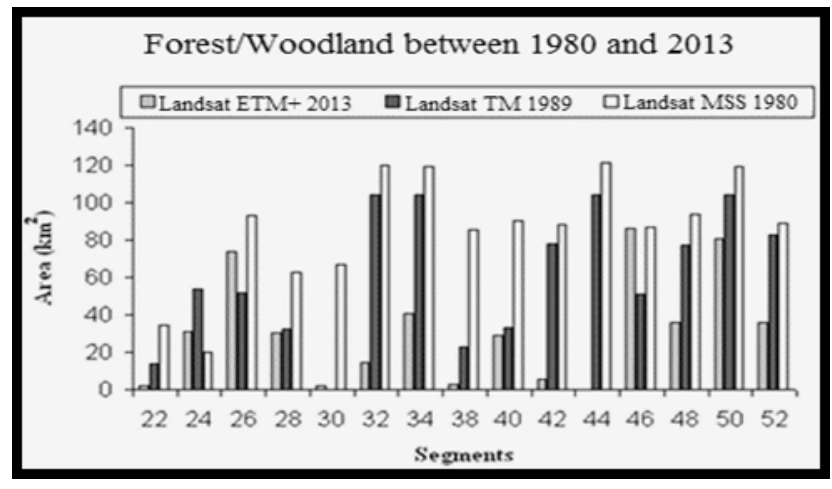

Figure 2: Forest and woodland between 1980 and 2013. 


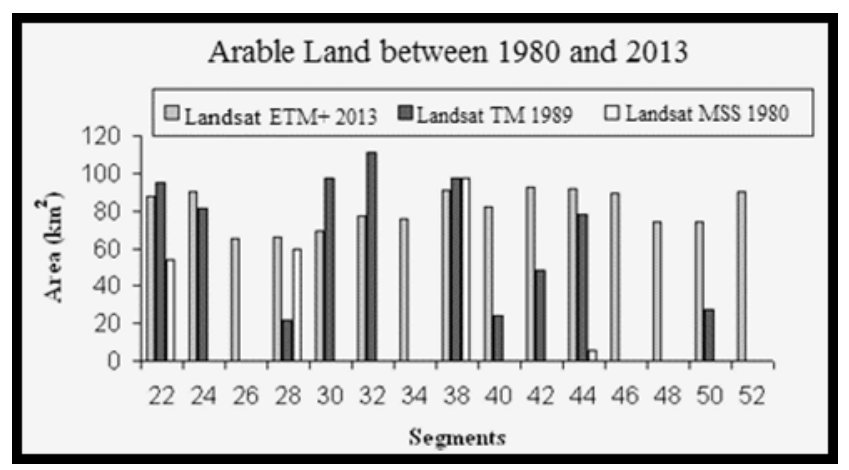

Figure 3: $\quad$ Arable land between 1980 and 2013.

Agricultural fields in some segments were noted to have increased from $31 \%$ to $79 \%$ during the period under consideration. A limiting factor in the use of imagery was that due to decrease of spatial resolution on the images, the dominant land cover types of forest and mixed farming exhibited a rapid increase and overestimation at the coarse levels of spatial aggregation at the expense of non-dominant land cover types like rural built-up lands. The dominant land cover types were overestimated due to spatial mixing of covers hence the high variances.

The error matrix shown in Table 1 indicated values between $78 \%$ and $86 \%$ for the overall user's accuracy and $67 \%$ and $80 \%$ for Kappa index which were used as the measure of actual agreement and the expected chance. Values within these ranges normally indicated good representations of the actual land cover. But more specifically, forest and water cover classes compared very well with the ground truth information and the reference datasets.

Table 1: The error matrix for image classification.

\begin{tabular}{|c|c|c|c|c|c|c|}
\hline \multirow[t]{2}{*}{ Land cover } & \multicolumn{2}{|c|}{$\begin{array}{c}\text { Landsat MSS } \\
(1973)\end{array}$} & \multicolumn{2}{|c|}{$\begin{array}{c}\text { Landsat TM } \\
\text { (1986) }\end{array}$} & \multicolumn{2}{|c|}{$\begin{array}{l}\text { Landsat ETM+ } \\
\text { (2013) }\end{array}$} \\
\hline & $\begin{array}{c}\text { Producer's } \\
(\%)\end{array}$ & $\begin{array}{c}\text { User's } \\
(\%)\end{array}$ & $\begin{array}{c}\text { Producer's } \\
(\%)\end{array}$ & $\begin{array}{c}\text { User's } \\
(\%)\end{array}$ & $\begin{array}{c}\text { Producer's } \\
(\%)\end{array}$ & $\begin{array}{c}\text { User's } \\
(\%)\end{array}$ \\
\hline Forest & 96 & 77 & 97 & 79 & 98 & 90 \\
\hline Buildup land & 88 & 78 & 98 & 79 & 100 & 89 \\
\hline Shrub land & 55 & 87 & 86 & 65 & 87 & 82 \\
\hline Agriculture & 81 & 92 & 85 & 94 & 89 & 97 \\
\hline Grassland & 50 & 86 & 75 & 86 & 86 & 88 \\
\hline Bananas & 85 & 70 & 94 & 89 & 98 & 82 \\
\hline Water & $\underline{100}$ & 100 & 100 & 100 & 100 & 100 \\
\hline Overall accuracy (\%) & \multicolumn{2}{|l|}{78} & \multirow{2}{*}{\multicolumn{2}{|c|}{81}} & \multicolumn{2}{|c|}{86} \\
\hline Kappa index (\%) & \multicolumn{2}{|l|}{67} & & 67 & \multicolumn{2}{|c|}{80} \\
\hline
\end{tabular}


Two accuracy metrics in this matrix demonstrated that the greatest areas of classification confusion were agriculture user's accuracy and urban and periurban producer's accuracy. Agriculture had $21.9 \%$ commission error, while urban and peri-urban had $37.7 \%$ commission error. Although confusion was found with all other categories, the commission for agriculture and urban and peri-urban was the most pronounced.

\subsection{Rainfall-runoff relationship}

Figure 4 shows the spatial distribution of streamflow stations in the catchment, which were used to evaluate the runoff simulations. Each station had a weir for the purpose of measuring discharges from sub-catchment drainage areas. The GIS generated drainage areas for the weirs were $507.2 \mathrm{~km}^{2}$ for weir A9H020; $609.3 \mathrm{~km}^{2}$ for weir A9H005; $16.1 \mathrm{~km}^{2}$ for weir A9H006 and $913.9 \mathrm{~km}^{2}$ for weir A9H001.

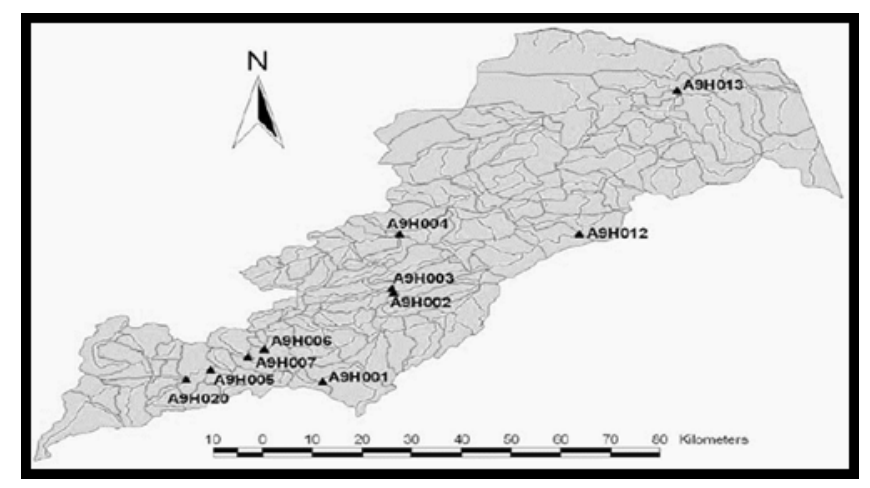

Figure 4: The spatial distribution of streamflow stations in the catchment.

Runoff and flood peaks corresponding to return periods of 2, 5, 10, 50, 100 and 200 years were estimated. To assess the effect of floods within built-up areas, the degree of protection was considered for floods which occur once in 100 or 200 years. Each computed flood magnitude was determined at $95 \%$ confidence interval which contained the true flood magnitude for a particular exceedance probability. Annual maximum daily flood discharge series were extracted for each hydrological year. The long-term (1962-2013) average rainfall value of $1012.029 \mathrm{~mm}$ per annum was obtained for the catchment using the Thiessen Polygon method. In analysing long term rainfall and runoff relationships, estimated values using curve numbers were related to variation in rainfall assuming the relationship between the two would be linear. The correlation obtained by linear regression was, $r^{2}=0.9739$ which represented a very significant direct relationship between the two parameters. The analysis of discharges showed that there was no direct relationship between rainfall and discharge. One could attribute it to the complex nature of land use in the area by the small holder farmers. It is possible that the overcrowded and congested 
land units carrying crops, woodlots, buildings and grasses detain and expose rain water to evaporation without allowing infiltration and hence prevent it from reaching the streams by interflow.

\subsection{Simulated runoff volumes}

The highest change in the runoff coefficient for the period of 1962-2013 was noted in the sub-catchments located in the upstream of the catchment. During this period, the runoff coefficients increased in a similar fashion. The flood hydrographs shown in Figure 5 illustrated how the scenario analysis compared in terms of flood peak discharges and the associated volumes. It was derived from the results that sub-catchment A91F at gauging station $\mathrm{A} 9 \mathrm{H} 001$ produced peak discharges of $128 \mathrm{~m}^{3} / \mathrm{s}$ for scenario $1,75 \mathrm{~m}^{3} / \mathrm{s}$ for scenario $2,50 \mathrm{~m}^{3} / \mathrm{s}$ for scenario 3 and $125 \mathrm{~m}^{3} / \mathrm{s}$ for 2013 . sub-catchment $\mathrm{A} 91 \mathrm{E}$ at gauging station A9H006 produced peak discharges of $150 \mathrm{~m}^{3} / \mathrm{s}, 110 \mathrm{~m}^{3} / \mathrm{s}, 75 \mathrm{~m}^{3} / \mathrm{s}$ and $180 \mathrm{~m}^{3} / \mathrm{s}$; subcatchment $\mathrm{A} 91 \mathrm{D}$ at gauging station $\mathrm{A} 9 \mathrm{H} 005$ produced peak discharges of $900 \mathrm{~m}^{3} / \mathrm{s}, 580 \mathrm{~m}^{3} / \mathrm{s}, 400 \mathrm{~m}^{3} / \mathrm{s}$ and $890 \mathrm{~m}^{3} / \mathrm{s}$ while sub-catchment A91A at gauging station A9H020 produced peak discharges of $680 \mathrm{~m}^{3} / \mathrm{s}, 420 \mathrm{~m}^{3} / \mathrm{s}, 310 \mathrm{~m}^{3} / \mathrm{s}$ and $300 \mathrm{~m}^{3} / \mathrm{s}$ for the same periods respectively. The $60 \mathrm{~mm}$ synthetic storm represented a typical storm event related to ITCZ for the respective subcatchments in the catchment. The simulated floods for all sub-catchments conformed approximately to a normal flood event with a return period of 2 years in the catchment. From the results, sub-catchments A91A and A91D had the highest increase in peak discharges. From the simulations, the derived composite values for $\mathrm{CN}$ values significantly changed the sub-catchments hydrologic response over the period.

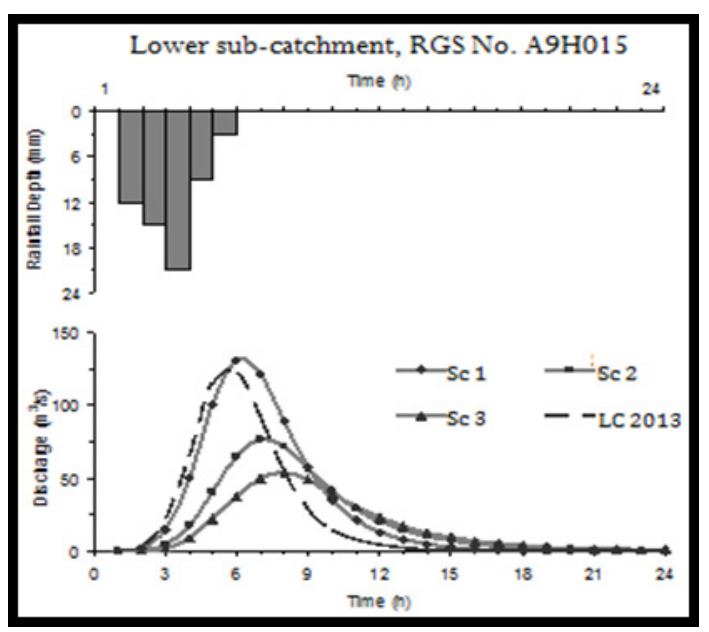

Figure 5: Flood hydrographs for the $60 \mathrm{~mm}$ synthetic storm event for the lower sub-catchments. 
The changes in discharge values represented an overall increase of $17 \%$ between 1962 and 2013. Also noted were the decreasing times to peak, with the similar events taking one hour more to reach the peak than before. The flood time to peak indicated a decreasing trend, in the range of 0.5 to 1 hour within the years. This represented a deteriorating situation in land cover conditions with increasing cultivation and expanding villages. Flood volumes on the other hand increased by $11 \%$ over the entire period of study.

\subsection{Flood frequency and magnitude}

In the recent years, the catchment has experienced floods resulting from higher than normal rainfall associated with the ITCZ and cyclonic episodes. The severity of floods is compounded by the after effects caused by lack of housing, starvation and disease. The South African National Disaster Management Centre estimated that more than 100,000 people live in the flood plains, below water levels previously reached by floods. When severe floods occur, people who live in flood plains close to rivers are at the risk of losing their lives, while their houses and farms may be destroyed. The increase in flood frequency and magnitude suggested that climate variability has an effect on the catchment. Based on the results, the computations showed that an increase in the peak discharges was to be expected, especially for the discharge range corresponding to smaller and medium flood magnitudes. The Gumbel models showed increasing discharges at higher probabilities of exceedance for all return periods, which could be associated with the effects of land cover change. Figure 6 shows the probabilistic plot of return periods based on Gumbel's distribution for station A9H003 located in upstream of the catchment.

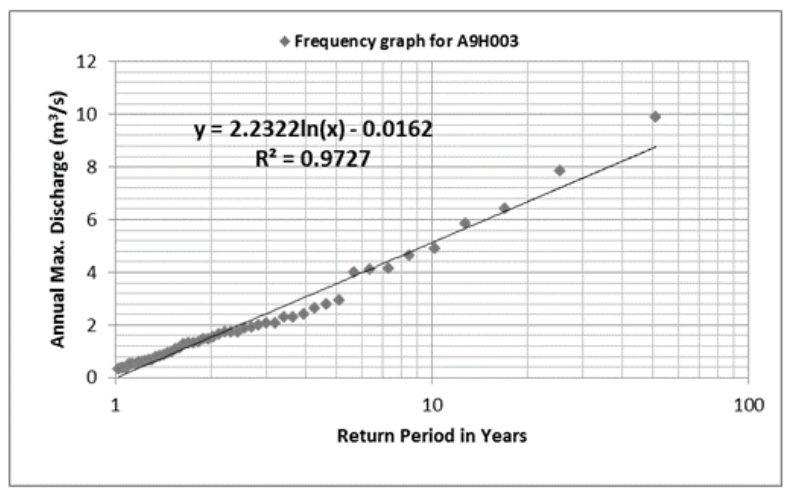

Figure 6: Probabilistic plot of return periods based on Gumbel's.

Given climate variability and the rapid land use changes in the catchment, a significant rise in water levels would lead to an increase in potential flood damage, particularly for flood events of lower to medium extremity, reducing flood security for the existing population. The effect would however be less for events with a lower probability of occurrence involving large floods like the 100 
and 200 year return period floods. A strategy of preserving natural forests and investing in sustainable agriculture, especially in uplands, could significantly reduce potential losses caused by the effects of degradation. The results showed that an increase in the peak discharges was to be expected, especially for small and medium floods. This could be associated with the effects of land cover change and anthropogenic factors. The flood volumes were noted to have increased by at least $11 \%$ over the same period of time. The flood time to peak indicated a decreasing trend, in the range of 0.5 to 1 hour within the years.

\section{Conclusions}

The integration of remotely sensed data with ancillary and hydrogeological data for spatial analysis and modeling within GIS, produced results showing land cover change and the corresponding peak discharges. The utility of per-pixel classification in analysing satellite data generated land cover classes with user's accuracy of between $78 \%$ and $86 \%$. The dominant land cover types were urban and peri-urban, agriculture, rangeland and forest. The simulated results indicated that the land cover changes affected the hydrological response of the basin leading to increased peak discharges and runoff volumes. The peak discharges in the whole catchment were noted to have increased by at least $17 \%$ over the period. In some cases, changes in the peak discharges in the sub-catchments were noted to decrease with increase in the rainfall amounts, indicating the possibility that the land cover changes may not have had a very strong influence during large storm events. When severe floods occur, people who live close to rivers are at the risk of losing their lives; while their houses and farms may be destroyed.

\section{References}

[1] DWAF, "Levuvhu and Letaba Water Management Area. Overview of water resources availability and utilization". Department of Water Affairs and Forestry, Pretoria, South Africa, 2003.

[2] Moore, I. D., Grayson, R. B. \& Ladson, A. R., Digital terrain modeling: a review of hydrological, geomorphological and biological applications, Hydrological processes, 5, pp. 3-30, 1991.

[3] Carpenter, T. M., Sperfslage, J. A., Georgakakos, K. P., Sweeney, T. \& Fread, D. L., National threshold runoff estimation utilizing GIS in support of operational flash flood warning systems, Journal of Hydrology, 224 (12), pp. 21-44, 1999.

[4] Coppin, P., Jonckheere, I., Nackaerts, K., Muys, B., \& Lambin E., Digital change detection methods in ecosystem monitoring: a review". International Journal of Remote Sensing, vol. 25, pp. 1565-1596, 2004.

[5] DWAF, A proposed National Water Resources Strategy for South Africa, Department of Water Affairs and Forestry, Pretoria, South Africa. 2002.

[6] Reddy, S.J., Suggested farming systems and associated risks over southern Mozambique. Comunicação No. 24, Série Terra e Água, INIA. Maputo, 1985. 
[7] Yuan, F., Sawaya, K. E., Loeffelholz, B. C., \& Bauer, M. E. (2005) Land cover classification and changes analysis of the twin cities (Minnesota) Metropolitan Area by multitemporal Landsat remote sensing. Journal of Remote Sensing and Environment, 98 pp. 317-328.

[8] Congalton, R.G. \& Green, K., Assessing the Accuracy of Remotely Sensed Data, CRC Press, Boca Raton, FL., 1999.

[9] FAO, "World reference base for soil resources". World Soil Resources Report No. 84. Rome, 1998.

[10] E. J. Gumbel, "The return period of flood flows" Ann. Math. Statist, 12(2), pp. 163-190, 1941.

[11] Hydrologic Modeling System-HEC-HMS, Technical Reference Manual, US Army corps of Engineers Hydrologic Engineering Centre, Davis, California, USA, 2000.

[12] Hydrologic Modeling System-HEC-HMS, Engineering Manual: Flood Runoff analysis, US Army corps of Engineers Hydrologic Engineering Centre, Davis, California, USA, 1994.

[13] Cunge, J. A., On the Subject of a Flood Propagation Computation Method (Muskingum Method)". Journal of Hydraulic Research, 7(2), pp. 205-230, 1969.

[14] Cowan, W.L., Estimating hydraulic roughness coefficients, Agricultural Engineering, 37 (7), pp. 473-475, 1956.

[15] Kundu, P.M. Singo, R.L., Odiyo, J.O., Mathivha, F.I. \& Nkuna, T.R., Extraction and Analysis of Morphologic and Hydrologic Properties for Luvuvhu River catchment in Limpopo Province, South Africa, in Water and Society II, C. A. Brebbia, Wessex Institute of technology: UK, WIT press, 178, pp. 29-39, 2014. 